\title{
Myocardial Infarction
}

Available online at www.hjhs.co.in

REVIEW ARTICLE

Abhishek Kumar Singh* and Dr Rakesh Kumar Jat

Institute of Pharmacy, Shri Jagdishprasad Jhabarmal Tibrewala University

Jhunjhunu (Rajasthan) India -333001.

DOI 10.22270/hihs.v6i4.116

\section{ABSTRACT}

Myocardial infarction (MI), commonly known as a heart attack is the disease of the blood vessels supplying the heart muscle (Myocardium) i.e. coronary heart disease. The area of heart muscle that has either zero flow or so little flow that it cannot sustain cardiac muscle function is said to be infracted and the overall process is called a myocardial infarction. MI are of two types; transmural and subendocardial. Mainly it is caused due to oxidative stress and atherosclerosis.Chest pain is the most common symptom of acute MI and is often described as a sensation of tightness, pressure, or squeezing. Other symptoms include diaphoresis (an excessive form of sweating), Shortness of breath (dyspnea), weakness, lightheadedness, nausea, vomiting, and palpitations. The most common symptoms of MI in women include dyspnea, weakness, and fatigue, sleep disturbances. It can be treated by using blockers, diuretics, ACE inhibitors, calcium channel blockers and nitrates.

Keywords: Myocardial Infarction; Atherosclerosis; Transmural: Subendocardial: Oxidative Stress

\section{Introduction}

Myocardial infarction (MI), commonly known as a heart attack is the disease of the blood vessels supplying the heart muscle (Myocardium) i.e. coronary heart disease. The area of heart muscle that has either zero flow or so little flow that it cannot sustain cardiac muscle function is said to be infracted and the overall process is called a myocardial infarction. (1)

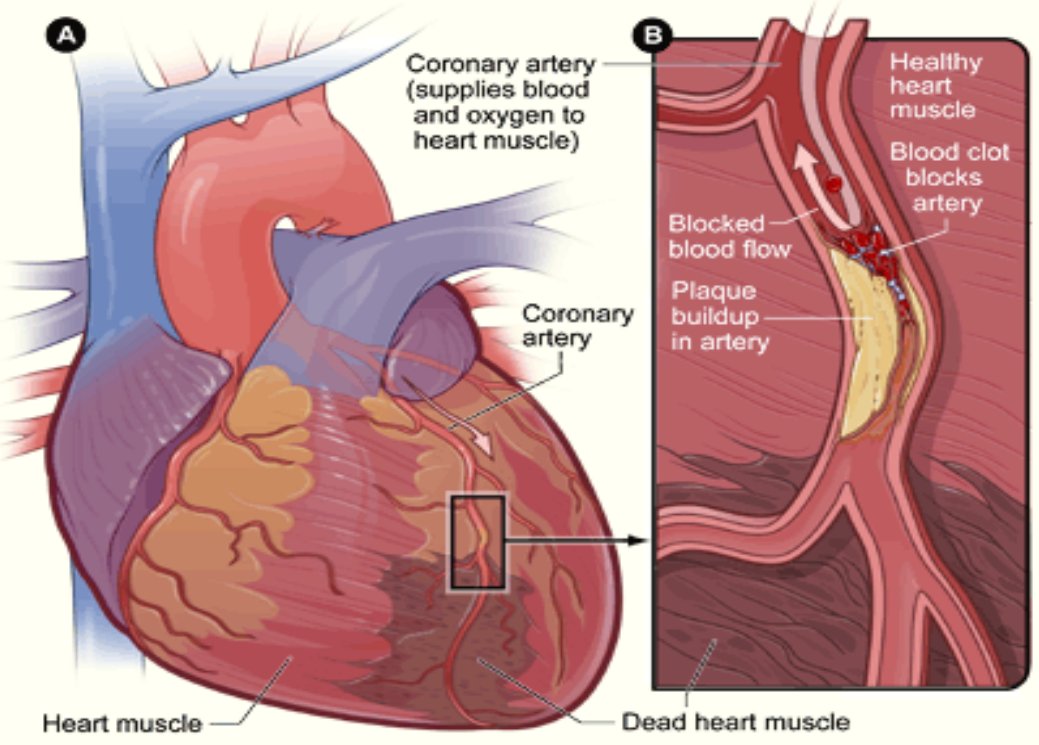

Figure 1.1 Myocardial infarction (Source: web-books.com)

Soon after the onset of the infarction, the area to become overfilled with stagnant blood as a combined effect of collateral blood flow through anastigmatic channel to the infracted area and progressive dilation of local blood vessels. 
Simultaneously the muscle fibers use the last vestiges of the oxygen in the blood, causing the hemoglobin to become totally de-oxygenated. Therefore, the infracted area takes on a bluish-brown. In later stages, the vessel walls become highly permeable and leak fluid; the local muscle tissue becomes edematous, and the cardiac muscle cells begin to swell because of diminished cellular metabolism. Within a few hours of almost no blood supply, the cardiac muscle cells die. Cardiac muscle requires about 1.3 milliliters of oxygen per 100 grams of muscle tissue per minute just to remain alive. (1)

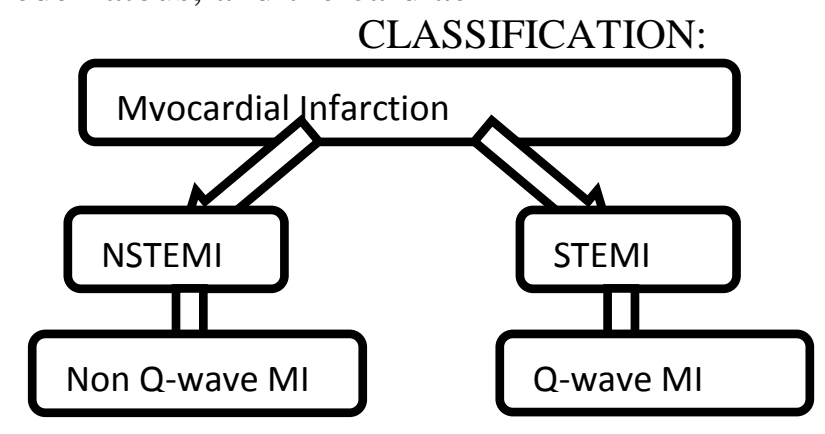

Figure 1.2 Classification of MI.

There are two basic types of MI:

Transmural: associated with atherosclerosis involving major coronary artery. It can be sub classified into anterior, posterior, or inferior. Transmural infarcts extend through the whole thickness of the heart muscle and are usually a result of complete occlusion of the area's blood supply.

Subendocardial: involves small area in the subendocardial wall of the left ventricle, ventricular septum, or papillary muscles. Subendocardial infarcts are thought to be a result of locally decreased blood supply, possibly from a narrowing of the coronary arteries. The Subendocardial area is farthest from the heart's blood supply and is more susceptible to this type of pathology.

Clinically, MI is further sub classified into ST elevation MI versus non ST elevation MI based on ECG changes.

\section{Epidemiology}

MI is a common presentation of ischemic heart disease. The WHO estimated that in 2002, 12.6 percent of deaths worldwide were from ischemic heart disease. (2) In the United States, diseases of the heart are the leading cause of death, causing a higher mortality than cancer (malignant neoplasm). (3) Coronary heart disease is responsible for 1 in 5 deaths in the U.S.This means that roughly every 65 seconds, an American dies of a coronary event. (4)

In India, cardiovascular disease (CVD) is the leading cause of death. (5) The deaths due to CVD in India were $32 \%$ of all deaths in 2007 and are expected to rise from 1.17 million in 1990 and 1.59 million in 2000 to 2.03 million in 2010. (6) Although a relatively new epidemic in India, it has quickly become a major health issue with deaths due to CVD expected to double during 1985-2015. (7-9)

\section{Legal Implication}

At common law, MI is generally a disease, but may sometimes be an injury. This has implications for no-fault insurance schemes such as workers' compensation. A heart attack is generally not covered (10); however, it may be a work-related injury if it results, for example, from unusual emotional stress or unusual exertion. (11) Additionally, in some jurisdictions, heart attacks suffered by persons in particular occupations such as police officers may be classified as lineof-duty injuries by statute or policy. In some countries or states, a person who has 
suffered from a MI may be prevented from participating in activity that puts other people's lives at risk, for example driving a car or flying an airplane. (12)

\section{Causes}

\section{1) Oxidative Stress}

Oxidative stress is caused by an imbalance between the production of reactive oxygen and a biological system's ability to readily detoxify the reactive intermediates or easily repair the resulting damage. All forms of life maintain a reducing environment within their cells. This reducing environment is preserved by enzymes that maintain the reduced state through a constant input of metabolic energy. A particularly destructive aspect of oxidative stress is the production of reactive oxygen species (ROS), which include free radicals and peroxides. Disturbances in this normal redox state can cause toxic effects through the production of peroxides and free radicals that damage all components of the cell, including proteins, lipids and DNA. In humans, oxidative stress is involved in many diseases, such as atherosclerosis, MI. (13)

ROS are metabolites of oxygen that can either strip electrons away from other molecules (oxidize), donate electrons to molecules (reduce), or react with and become part of molecules (i.e., oxidative modification). A particularly important radical for cardiovascular biology is superoxide $\left(\mathrm{O}_{2}{ }^{-}\right)$, which is formed by the one-electron reduction of oxygen. $\left(\mathrm{O}_{2}{ }^{-{ }^{-}}\right)$is important because it can serve as both an oxidant and as a reductant in biologic systems and is a progenitor for other ROS. Endogenous production of free radicals occurs during normal aerobic metabolism. Activated oxygen intermediates are formed by stepwise reduction of $\mathrm{O}_{2}$ to water and by secondary reactions with protons and transition metals such as $\mathrm{Fe}$ and $\mathrm{Cu}$. The superoxide anion $\left(\mathrm{O}_{2}{ }^{-}\right)$is produced by many cell redox systems including ischemia-derived xanthine oxidase, aldehyde oxidase and membraneassociated NADPH oxidases. In addition, phagocytic cells, including macrophages and monocytes, increase their $\mathrm{O}_{2}$ uptake when stimulated and release large amounts of $\mathrm{O}_{2}{ }^{--}$into the extracellular fluid through the action of NADPH oxidase. Although $\mathrm{O}_{2}{ }^{-}$is not particularly reactive, having a low second-order rate constant with biomolecules, it is capable of diffusing through relatively large distances through the cell where, in the presence of $\mathrm{Fe}$ and $\mathrm{Cu}, \quad$ a metal-catalysed Haber-Weiss reaction is thought to occur resulting in the formation of the highly reactive hydroxyl radical $\left(\mathrm{OH}^{\circ}\right)$. (14)

Other radicals include the lipid peroxy(LOO') radical, and alkoxy- radicals ( $\mathrm{LO}^{\circ}$ ). Other molecules, including peroxynitrite $\left(\mathrm{ONOO}^{-}\right)$, hypochlorous acid $\left(\mathrm{HOCl}^{-}\right)$, and hydrogen peroxide $\left(\mathrm{H}_{2} \mathrm{O}_{2}\right)$ are not radicals but have strong oxidant properties and are, therefore, included as ROS. (15) Another relevant group of molecules are the reactive nitrogen species (RNS) including nitric oxide (NO), the nitrogen dioxide radical $\left(\mathrm{NO}_{2}{ }^{\circ}\right)$, and the nitrosonium cation $\left(\mathrm{NO}^{+}\right)$. Peroxynitrite is considered both an ROS and RNS and is formed by the near diffusion-limited reaction between $\mathrm{O}_{2}{ }^{-}$and NO. RNS are important, because they often react with and modify proteins and other cellular structures and alter function of these targets. $(16,17)$

In addition to ROS-forming enzymes, mammalian cells produce myriad molecules and enzymes that remove ROS. Some of these are small molecules, such as the thiol-containing tripeptide glutathione. Others are enzymes that catalyze removal of ROS, such as the superoxide dismutases (SODs), which catalyze dismutation of $\mathrm{O}_{2}{ }^{--}$to $\mathrm{H}_{2} \mathrm{O}_{2}$ and water; catalase, which converts $\mathrm{H}_{2} \mathrm{O}_{2}$ to oxygen and water; the glutathione peroxidases, which use $\mathrm{H}_{2} \mathrm{O}_{2}$ and glutathione as co-substrates to form water and glutathione disulfide; thioredoxin; and others. (18) 
Sources of reactive oxygen/nitrogen species:

\section{NAD(P)H oxidases (Nox)}

The phagocytes, including neutrophils, monocytes, and macrophages, contain a plasma membrane-bound multicomponent oxidase that utilizes NADPH-derived electrons and Activation of the oxidase in phagocytic cells results in large amounts of $\mathrm{O}_{2}{ }^{-}$over short periods that appear to be involved in host defense. $\mathrm{NAD}(\mathrm{P}) \mathrm{H}$ oxidases in vascular cells are subject to activation by specific agonists that include angiotensin II, thrombin, platelet-derived growth factor, tumor necrosis factor- $\alpha$, interleukin-, and, for endothelial cells, mechanical forces (including shear stress) and vascular endothelial growth factor. $(19,20)$

\section{Xanthine oxidase}

Xanthine oxidase is an iron-sulfur molybdenum flavoprotein with multiple functions that exists in two forms, xanthine dehydrogenase and xanthine oxidase, the former being predominant. The oxidation of xanthine or hypoxanthine to uric acid is associated with NADH production by the dehydrogenase, whereas the oxidase generates $\mathrm{O}_{2}{ }^{-}$. The dehydrogenase is readily converted into the oxidase by proteolysis or by reversible oxidation of thiol groups. Xanthine oxidase contributes to impaired $\cdot \mathrm{NO}$ bioactivity observed with hypercholesterolemia, heavy smoking, and coronary disease. (21)

\section{Nitric oxide synthases}

A relative cofactor deficiency for enzyme catalysis allows the enzyme to reduce molecular oxygen rather than transfer electrons to Larginine, thereby generating $\mathrm{O}_{2}{ }^{-}$by the oxygenase domain of the enzyme through dissociation of a ferrous-dioxygen complex that is normally stabilized by tetrahydrobiopterin. In atherosclerosis and diabetes there is evidence that vascular tetrahydrobiopterin levels may be depressed. Nitric oxide may react with metal ions, metalloproteins, and $\mathrm{O}_{2}{ }^{-}$to form reactive nitrogen species. Perhaps the best characterized of these reactions is the combination of $\mathrm{NO}$ and $\mathrm{O}_{2}{ }^{--}$to generate $\mathrm{ONOO}^{-}$. Among the most abundant biological targets for $\mathrm{ONOO}^{-}$is carbon dioxide $\left(\mathrm{CO}_{2}\right)$. The reaction of $\mathrm{ONOO}^{-}$with $\mathrm{CO}_{2}$ is complex and initially produces nitrosoperoxycarbonate which homolyzes to form a pair of caged radicals that may then diffuse apart to become free radicals, or recombine to form nitro carbonate $\left(\mathrm{O}_{2} \mathrm{NOCO}_{2}\right)$, which decomposes to nitrite and $\mathrm{CO}_{2}$. The formation of free nitrogen dioxide $\left(\mathrm{NO}_{2}\right)$ readily leads to protein tyrosine nitration and lipid peroxidation. (19-21)

\section{Myeloperoxidase}

Myeloperoxidase is the only human enzyme that generates $\mathrm{HOCl}$; chlorinated biomolecules are considered specific markers of MPO-mediated oxidation reactions. Myeloperoxidase can yield a number of products, including 3chlorotyrosine, chlorohydrins from cholesterol and fatty acids, and tyrosyl radicals, with the latter species able to participate in single electron oxidation reactions, including the oxidation of LDL. Another activity of myeloperoxidase and $\mathrm{HOCl}$ is to convert L-tyrosine into phydroxyphenylacetaldehyde which can react with amino phospholipids and the $\varepsilon$ amino groups of protein lysine residues. The product of these reactions may be subsequently modified by myeloperoxidase to generate a variety of reactive aldehyde residues. Furthermore, L-serine is readily converted by myeloperoxidase to $\mathrm{Ne}$ - (carboxymethyl) lysine, a well-characterized advanced glycation end-product. Thus, myeloperoxidase and $\mathrm{HOCl}$ can generate a series of secondary oxidation products that may oxidize biomolecules, including LDL, rendering them capable of converting macrophages into foam cells. $(19,20)$

\section{Mitochondrial respiration}


Conventional wisdom dictates that up to $1-2 \%$ of electron flow through the respiratory chain may be diverted to molecular oxygen. Thus; one must consider the mitochondrion as a potential major intracellular source of reactive oxygen species. Mitochondrial oxidant production is controlled, in part, by the expression of a mitochondrial Mncontaining superoxide dismutase located in the mitochondrial matrix. (19-21)

\section{2) Atherosclerosis}

Atherosclerosis is the condition in which an artery wall thickens as the result of a buildup of fatty materials such as cholesterol. It is a chronic inflammatory response in the walls of arteries, in large part due to the accumulation of macrophage white blood cells and promoted by low density lipoproteins (plasma proteins that carry cholesterol and triglycerides) without adequate removal of fats and cholesterol from the macrophages by functional high density lipoproteins (HDL). Complications of atherosclerosis are chronic, slowly progressive and cumulative. Most commonly, soft plaque suddenly ruptures causing the formation of a thrombus that will rapidly slow or stop blood flow, leading to death of the tissues fed by the artery. This catastrophic event is called an infarction. One of the most common recognized scenarios is called coronary thrombosis of a coronary artery, causing MI. Even worse is the same process in an artery to the brain, commonly called stroke. (22)

Atherosclerosis develops from low-density lipoprotein molecules (LDL) becoming oxidized by free radicals, particularly oxygen free radicals (ROS). When oxidized LDL comes in contact with an artery wall, a series of reactions occur to repair the damage to the artery wall caused by oxidized LDL. The LDL molecule is globular shaped with a hollow core to carry cholesterol throughout the body to generate brain tissues, vitamin $\mathrm{D}$, and so on. Cholesterol does not dissolve in water. Cholesterol can move in the bloodstream only by being transported by LDL. $(1,20)$ The initial damage to the blood vessel wall results in a "call for help," an inflammatory response. Monocytes enter the artery wall from the bloodstream, with platelets adhering to the area of insult. This may be promoted by redox signaling induction of factors such as VCAM-1, which recruit circulating monocytes. The monocytes differentiate macrophages which ingest oxidized LDL, slowly turning into large "foam cells" - so-described because of their changed appearance resulting from the numerous internal cytoplasmic vesicles and resulting high lipid content. Unfortunately, these white blood cells are not able to process the oxidized-LDL, and ultimately grow then rupture, depositing a greater amount of oxidized cholesterol into the artery wall. This triggers more white blood cells, continuing the cycle. Eventually, the artery becomes inflamed. The cholesterol plaque causes the muscle cells to enlarge and form a hard cover over the affected area. This hard cover is what causes a narrowing of the artery, reduces the blood flow and increases blood pressure. (23)

\section{Symptoms of MI}

The onset of symptoms in MI is usually gradual, over several minutes, and rarely instantaneous. Chest pain is the most common symptom of acute MI and is often described as a sensation of tightness, pressure, or squeezing. Other symptoms include diaphoresis (an excessive form of sweating), Shortness of breath (dyspnea), weakness, light-headedness, nausea, vomiting, and palpitations. The most common symptoms of $\mathrm{MI}$ in women include dyspnea, weakness, and fatigue, sleep disturbances. In women, chest pain may be less predictive of coronary ischemia than in men. (24)

Approximately one fourth of all MI are silent, without chest pain or other 
symptoms. (25) These cases can be discovered later on electrocardiograms or at autopsy without a prior history of related complaints. A silent course is more common in the elderly, in patients with diabetes mellitus and after heart transplantation, probably because the donor heart is not connected to nerves of the host. (26)

\section{Risk factors}

Heart attack rates are higher in association with intense exertion, be it psychological stress or physical exertion, especially if the exertion is more intense than the individual usually performs. Quantitatively, the period of intense exercise and subsequent recovery is associated with about a 6-fold higher MI rate (compared with other more relaxed time frames) for people who are physically very fit. (27) For those in poor physical condition, the rate differential is over 35fold higher. (27) One observed mechanism for this phenomenon is the increased arterial pulse pressure stretching and relaxation of arteries with each heart beat which, as has been observed with intravascular ultrasound, increases mechanical "shear stress" on atheromas and the likelihood of plaque rupture. (27)

Acute severe infection, such as pneumonia, can trigger MI. A more controversial link is that between Chlamydophila pneumoniae infection and atherosclerosis. (28) While this intracellular organism has been demonstrated in atherosclerotic plaques, evidence is inconclusive as to whether it can be considered a causative factor. (28) Treatment with antibiotics in patients with proven atherosclerosis has not demonstrated a decreased risk of heart attacks or other coronary vascular diseases. (29)

There is an association of an increased incidence of a heart attack in the morning hours, more specifically around 9 a.m. (3032) Some investigators have noticed that the ability of platelets to aggregate varies according to a circadian rhythm, although they have not proven causation. (33) Some investigators theorize that this increased incidence may be related to the circadian variation in cortisol production affecting the concentrations of various cytokines and other mediators of inflammation. (34)

Risk factors for atherosclerosis are generally risk factors for MI:

- Diabetes (with or without insulin resistance) - the single most important risk factor for ischaemic heart disease (IHD)

- Tobacco smoking

- Hypercholesterolemia

(more accurately hyperlipoproteinemia, especially high LDL and low HDL)

- High blood pressure

- Family history of IHD

- Obesity (35) (defined by a body mass index of more than $30 \mathrm{~kg} / \mathrm{m}^{2}$, or alternatively by waist circumference or waist-hip ratio).

- Age: Men acquire an independent risk factor at age 45, Women acquire an independent risk factor at age 55; in addition individuals acquire another independent risk factor if they have a first-degree male relative (brother, father) who suffered a coronary vascular event at or before age 55 . Another independent risk factor is acquired if one has a first-degree female relative (mother, sister) who suffered a coronary vascular event at age 65 or younger.

- Hyperhomocysteinemia (high homocysteine, a toxic blood amino acid that is elevated when intakes of vitamins B2, B6, B12 and folic acid are insufficient)

- Stress (occupations with high stress index are known to have susceptibility for atherosclerosis)

- Alcohol Studies show that prolonged exposure to high quantities of alcohol can increase the risk of heart attack. 
Males are more at risk than females. (27)

\section{Mechanism of MI}

Fatty acids are the main fuel for the healthy heart, supplying approximately 60$80 \%$ of the energy. Myocardial ischemia dramatically alters fuel metabolism. (20) Sudden occlusion of a major branch of a coronary artery shifts aerobic or mitochondrial metabolism to anaerobic glycolysis within seconds. A compensatory increase in anaerobic glycolysis for ATP production leads to the accumulation of hydrogen ions and lactate, resulting in intracellular acidosis and inhibition of residual energy metabolism. (36) Impaired contraction with persistent electrical activity develops in association with alterations in ion transport systems in the sarcolemma and organellar membranes. (37) Reduced aerobic ATP formation stimulates glycolysis and an increase in myocardial glucose uptake and glycogen breakdown. At the same time decreased ATP inhibits $\mathrm{Na}^{+}, \mathrm{K}^{+}$-ATPase, increasing intracellular $\mathrm{Na}^{+}$and $\mathrm{Cl}^{-}$, leading to cell swelling. (38)

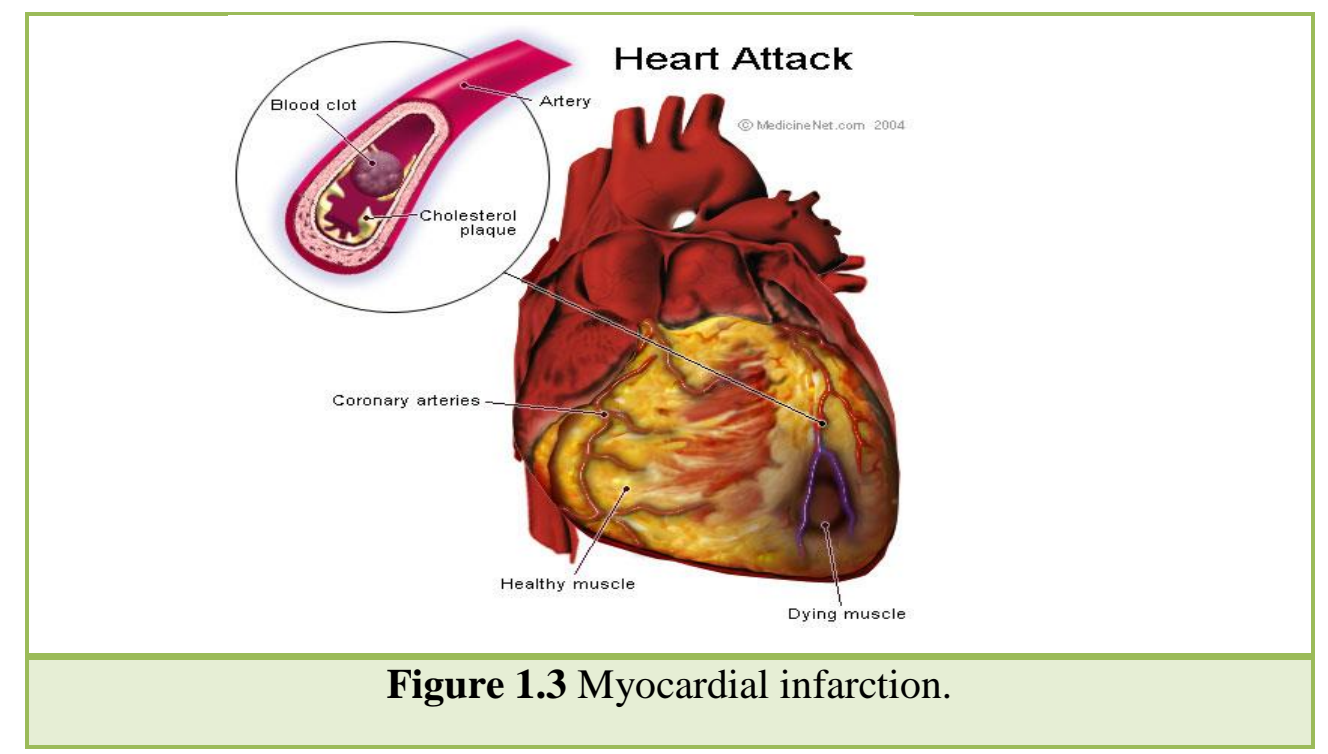

An early increase in cytosolic $\mathrm{Ca}^{2+}$ also develops due to multifactorial changes in transport systems in the sarcolemma and sarcoplasmic reticulum. $\mathrm{Ca}^{2+}$-induced activation of proteases causes alterations in contractile proteins, decreased sensitivity to $\mathrm{Ca}^{2+}$, and sustained impairment of contractility despite the elevated cytosolic $\mathrm{Ca}^{2+}$. (39)

Ultra structurally, reversibly injured myocytes are edematous and swollen from the osmotic overload. The cell size is increased with a decrease in the glycogen content. (40) Increased cytosolic $\mathrm{Ca}^{2+}$ and mitochondrial impairment cause phospholipase activation and release of lysophospholipids and free fatty acids, which are incorporated within the cell and damaged by per oxidative damage from free radicals and toxic oxygen species. (41)

\section{Pathophysiology}

A MI occurs when an atherosclerotic plaque slowly builds up in the inner lining of a coronary artery and then suddenly ruptures, totally occluding the artery and preventing blood flow downstream.

The most common triggering event is the disruption of an atherosclerotic plaque in an epicardial coronary artery, which leads to a clotting cascade, sometimes resulting in total occlusion of the artery. Atherosclerosis is the gradual buildup of cholesterol and fibrous tissue in plaques in the wall of arteries (in this case, the 
coronary arteries), typically over decades. Blood stream column irregularities visible on angiography reflect artery lumen narrowing as a result of decades of advancing atherosclerosis. Plaques can become unstable, rupture, and additionally promote a thrombus (blood clot) that occludes the artery; this can occur in minutes.
When a severe enough plaque rupture occurs in the coronary vasculature, it leads to MI (necrosis of downstream myocardium).

If impaired blood flow to the heart lasts long enough, it triggers a process called the ischemic cascade; the heart cells in the territory of the occluded coronary artery die (chiefly through necrosis) and do not grow back.

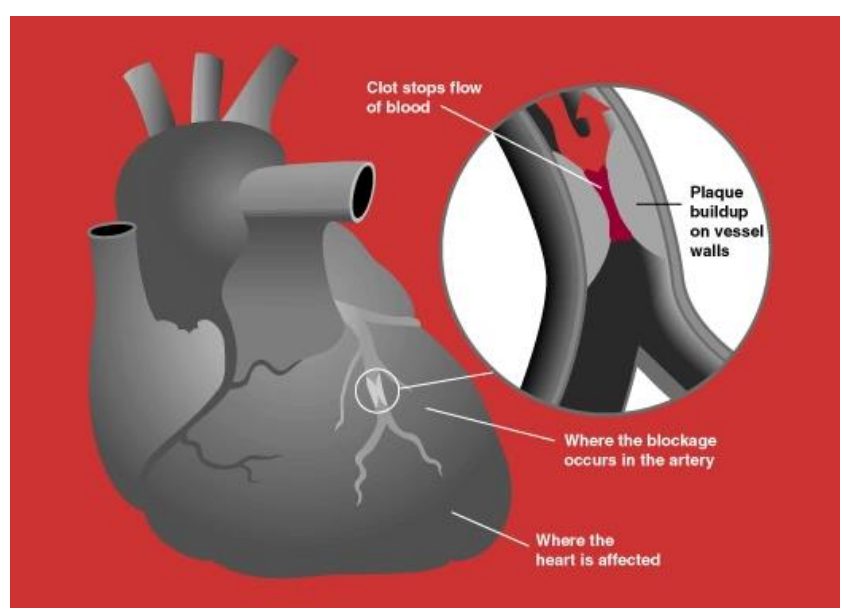

Figure 1.4 the inner lining of a coronary artery

A collagen scar forms in its place. Recent studies indicate that another form of cell death called apoptosis also plays a role in the process of tissue damage subsequent to MI. (42) As a result, the patient's heart will be permanently damaged. This Myocardial scarring also puts the patient at risk for potentially life threatening arrhythmias, and may result in the formation of a ventricular aneurysm that can rupture with catastrophic consequences.

Injured heart tissue conducts electrical impulses more slowly than normal heart tissue. The difference in conduction velocity between injured and uninjured tissue can trigger re-entry or a feedback loop that is believed to be the cause of many lethal arrhythmias. The most serious of these arrhythmias is ventricular fibrillation (V-Fib/VF), an extremely fast and chaotic heart rhythm that is the leading cause of sudden cardiac death. Another life threatening arrhythmia is ventricular tachycardia (V-Tach/VT), which may or may not cause sudden cardiac death.
However, ventricular tachycardia usually results in rapid heart rates that prevent the heart from pumping blood effectively. Cardiac output and blood pressure may fall to dangerous levels, which can lead to further coronary ischemia and extension of the infarct.

The cardiac defibrillator is a device that was specifically designed to terminate these potentially fatal arrhythmias. The device works by delivering an electrical shock to the patient in order to depolarize a critical mass of the heart muscle, in effect "rebooting" the heart. This therapy is time dependent, and the odds of successful defibrillation decline rapidly after the onset of cardiopulmonary arrest.

\section{Diagnosis Criteria}

\section{WHO criteria}

WHO criteria (43) have classically been used to diagnose MI; a patient is diagnosed with MI if two (probable) or three (definite) of the following criteria are satisfied: 
Clinical history of ischaemic type chest pain lasting for more than 20 minutes Changes in serial ECG tracings Change in serum cardiac biomarkers such as creatine kinase-MB fraction and troponin I.

The WHO criteria were refined in 2000 to give more prominence to cardiac biomarkers. (44) According to the new guidelines, a cardiac troponin, myoglobin rise accompanied by typical symptoms, pathological Q waves, ST elevation or depression or coronary interventions are diagnostic of MI.

\section{Electrocardiograph}

The electrocardiogram (ECG or EKG, abbreviated from the German Elektrokardiogramm) is a graphic recording of electric potentials generated by the heart. The signals are detected by means of metal electrodes attached to the extremities and chest wall and are then amplified and recorded by the electrocardiograph. ECG leads actually display the instantaneous differences in potential between these electrodes. (45)

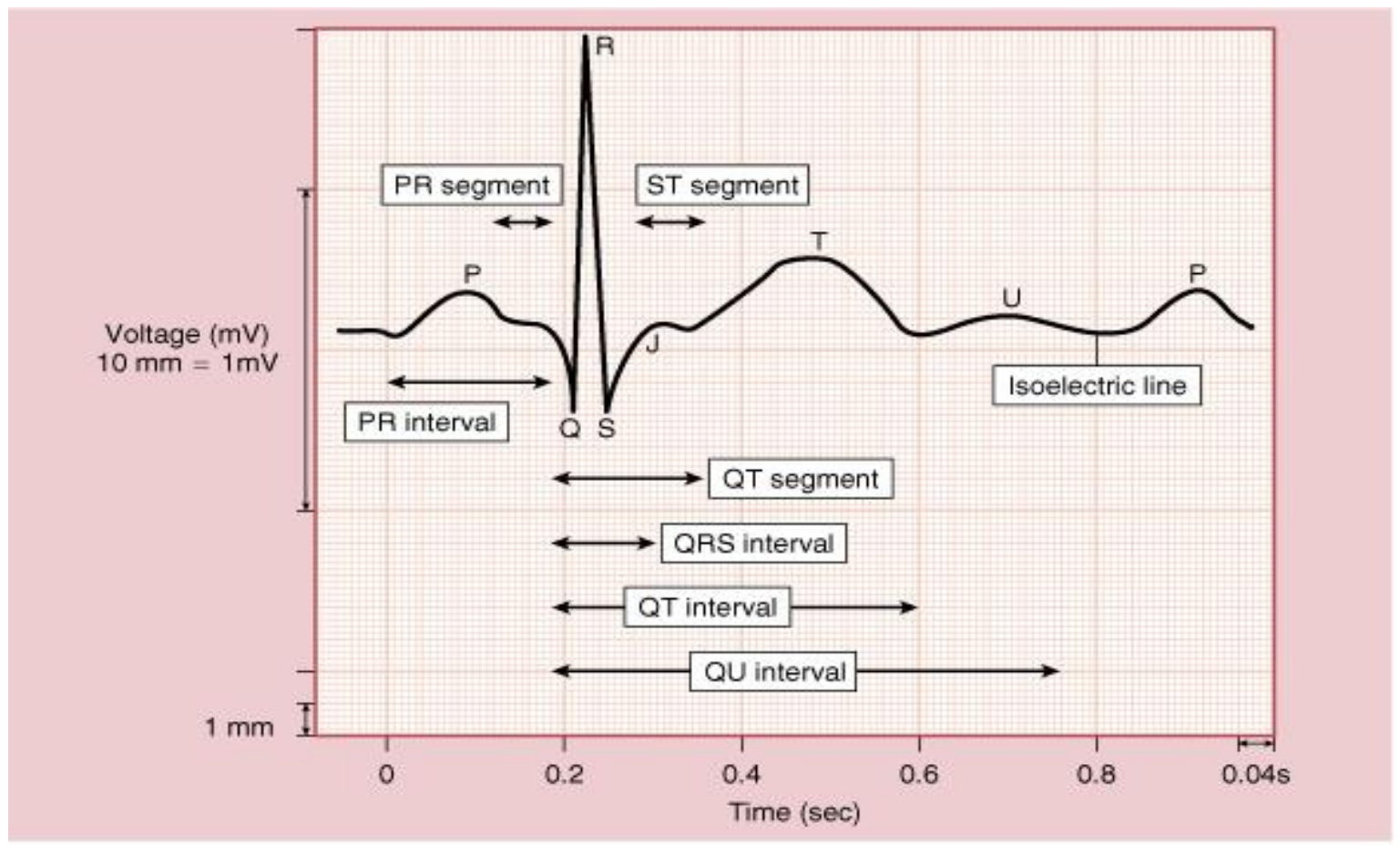

Figure 1.5 Electrocardiogram -I

The clinical utility of the ECG derives from its immediate availability as a noninvasive, inexpensive, and highly versatile test. In addition to its use in detecting arrhythmias, conduction disturbances, and myocardial ischemia, electrocardiography may reveal other findings related to life-threatening metabolic disturbances (e.g., hyperkalemia) or increased suspectibity to sudden cardiac death (e.g., QT prolongation syndromes). The advent of coronary thrombolysis or angioplasty in the early therapy of acute myocardial infarction has refocused particular attention on the sensitivity and specificity of ECG signs of myocardial ischemia. (46) Many cardiac abnormalities alter the heart's electrical activity, and cause changes in the ECG. Since the electrical activity of both atria and ventricles is reflected in the ECG, the test is of particular value in defining cardiac rhythm. Diseases which result in changes in the myocardial muscle mass will alter the ECG. Diseases which cause death of heart muscle and replacement by scar tissue (such as MI) will be reflected in 
characteristic changes in morphology of the QRS complex. Inadequate blood supply to heart muscle resulting from coronary artery disease may cause alterations in the repolarization of muscle cells, which will be reflected in characteristic changes in the ST-T wave portion of the electrocardiogram.

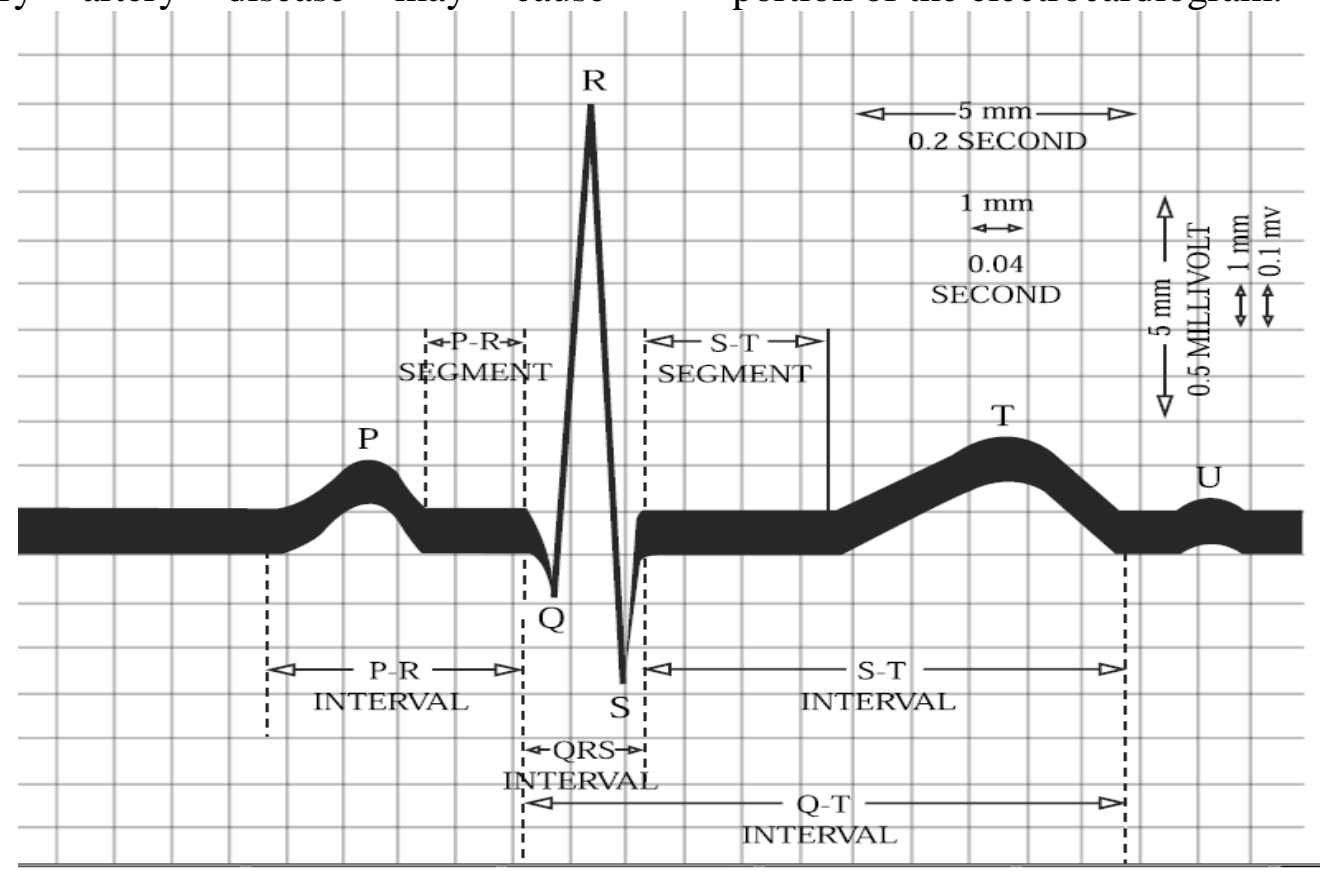

Figure 1.6 Electrocardiogram (47)

From left to right the first deflection seen in Figure 1.6 is labeled a P-wave. It represents the voltage change at the body's surface caused by the depolarization of the atria. Atrial depolarization is usually complete in about 0.1 seconds. Therefore, the P-wave usually spans about 2.5 millimeters. A P-wave typically stands 1-2 millimeters tall (0.1-0.2 millivolts).

Once the P-wave is completed, an isoelectric segment follows during which no surface potential is visible using ordinary equipment. During this time the cardiac action potential passes through the AV node and ventricular conduction system.

The interval from the beginning of the Pwave to the beginning of the QRS complex is called the PR interval and is normally no longer than 0.2 seconds in adults (Figure 1.6).

A wave corresponding to atrial repolarization occurs, but is ordinarily buried in the QRS complex, and is not identifiable in the ECG.
The QRS wave complex follows the PR segment. It represents ventricular depolarization, lasts approximately 80-100 milliseconds, and has amplitude of 0.5-1.0 millivolts. The QRS depolarization is much greater in amplitude than the $\mathrm{P}$-wave complex because of the greater muscular mass of the ventricle, and the greater synchronization of depolarization by the high speed ventricular conduction system. At the completion of the QRS complex, another segment of zero voltage normally follows: the ST segment. It corresponds to the plateau period of the action potential during which the ventricles remain depolarized. It typically lasts 150 milliseconds, but is a function of heart rate.

The T-wave follows the ST-segment, and corresponds to ventricular repolarization. Cellular repolarization is a much slower process than depolarization. Also, repolarization does not appear to propagate from cell to cell. Rather, individual cells repolarize independently depending on their individual plateau duration. Whereas 
depolarization spreads from endocardium to epicardium, repolarization normally proceeds in the opposite direction (the action potentials of epicardial cells are shorter than those of endocardial cells). Normal T-wave duration is 0.15-0.20 seconds, and normal amplitude in the limb leads is less than 0.6 millivolts (48)

\section{Electrophysiology}

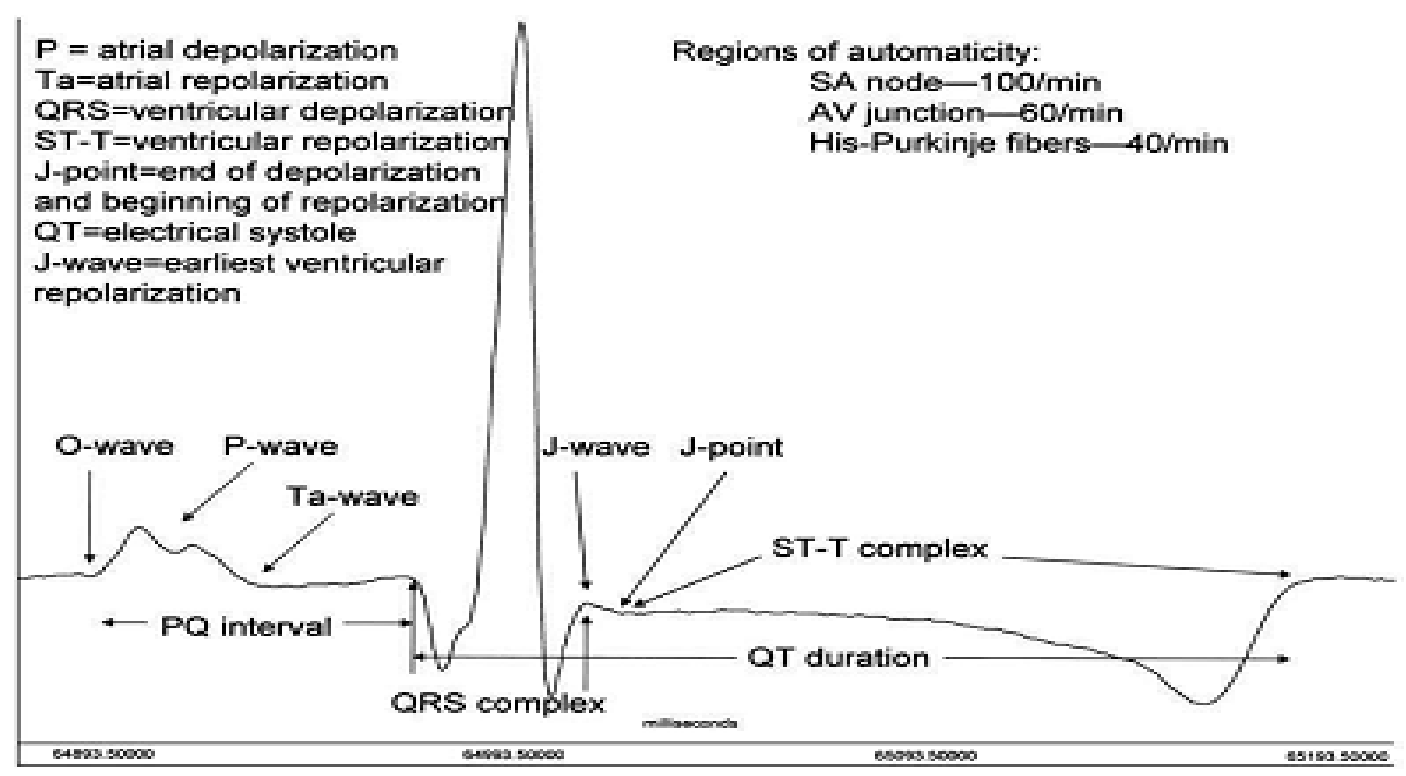

Figure 1.7 Electrocardiogram -II (43)

P wave is 110 milliseconds or less in duration; the first two-thirds are from right atrial depolarization, the last two-thirds from left atrial depolarization. In healthy person, the $\mathrm{P}$ wave is upright in lead II and biphasic in lead V1; the first, positive deflection is larger than the second, negative one.

PR interval is 120-200 milliseconds in duration. A short PR interval may indicate an accessory pathway, which allows early ventricular depolarization ('preexcitation'). A long PR interval reflects slow conduction through the AV node and bundle of His, and may indicate a conducting tissue disease predisposing to bradyarrhythmia through high-grade AV block. A PR interval of over 200 ms may indicate a first degree heart block. PR
Depolarization of the heart is the initiating event for cardiac contraction. The electric currents that spread through the heart are produced by three components: cardiac pacemaker cells, specialized conduction tissue, and the heart muscle itself. The ECG, however, records only the depolarization (stimulation) and repolarization (recovery) potentials generated by the atrial and ventricular myocardium. segment depression may indicate atrial injury or pericarditis.

QRS complex is 120 milliseconds or less in duration. The QRS complex corresponds to the depolarization of the ventricles. Because the ventricles contain more muscle mass than the atria, the QRS complex is larger than the $\mathrm{P}$ wave. In addition, because the His/Purkinje system coordinates the depolarization of the ventricles, the QRS complex tends to look "spiked" rather than rounded due to the increase in conduction velocity. The duration, amplitude, and morphology of the QRS complex is useful in diagnosing cardiac arrhythmias, conduction abnormalities, ventricular hypertrophy, myocardial infarction, electrolyte derangements, and other disease states. 
Q waves can be normal (physiological) or pathological. Normal Q waves, when present, represent depolarization of the interventricular septum. For this reason, they are referred to as septal Q waves. Q waves greater than $1 / 3$ the height of the $R$ wave, greater than $0.04 \mathrm{sec}(40 \mathrm{~ms})$ in duration, or in the right precordial leads are considered to be abnormal, and may represent myocardial infarction.

RT segment connects the QRS complex and the $\mathrm{T}$ wave and has duration of 80 to120 millisecond. It starts at the $\mathrm{J}$ point and ends at the beginning of the $\mathrm{T}$ wave. However, since it is usually difficult to determine exactly where the ST segment ends and the $\mathrm{T}$ wave begins, the relationship between the RT segment and $\mathrm{T}$ wave should be examined together.

ST segment is isoelectric. 'Physiological' ST elevation is usually restricted to leads V1 to V3/4. Flat, down sloping or depressed ST segments may indicate coronary ischemia. ST segment elevation may indicate myocardial infarction.

T wave represents the repolarization (or recovery) of the ventricles. The interval from the beginning of the QRS complex to the apex of the $T$ wave is referred to as the absolute refractory period. The last half of the $\mathrm{T}$ wave is referred to as the relative refractory period.
Inverted (or negative) $\mathbf{T}$ waves can be a sign of coronary ischemia, left ventricular hypertrophy. Tall or "tented" symmetrical $\mathrm{T}$ waves may indicate hyperkalemia. Flat $\mathrm{T}$ waves may indicate coronary ischemia or hypokalemia. The earliest electrocardiographic finding of acute myocardial infarction is sometimes the hyper acute $\mathrm{T}$ wave, which can be distinguished from hyperkalemia by the broad base and slight asymmetry.

QT interval is 0.30 and 0.44 seconds in duration. The QT interval is important in the diagnosis of long QT syndrome and short QT syndrome. The QT interval represents on an ECG the total time needed for the ventricles to depolarize and repolarize.

$\mathbf{U}$ wave is not always seen. It is typically small, and, by definition, follows the $\mathrm{T}$ wave. $U$ waves are thought to represent repolarization of the papillary muscles or Purkinje fibers. Prominent $U$ waves are most often seen in hypokalemia, but may be present in hypercalcemia, thyrotoxicosis, or exposure to digitalis, epinephrine, and Class $1 \mathrm{~A}$ and 3 antiarrhythmics, as well as in congenital long QT syndrome and in the setting of intracranial hemorrhage. An inverted $U$ wave may represent myocardial ischemia or left ventricular volume overload $(26,44)$

\section{Sequential changes of acute MI (44)}

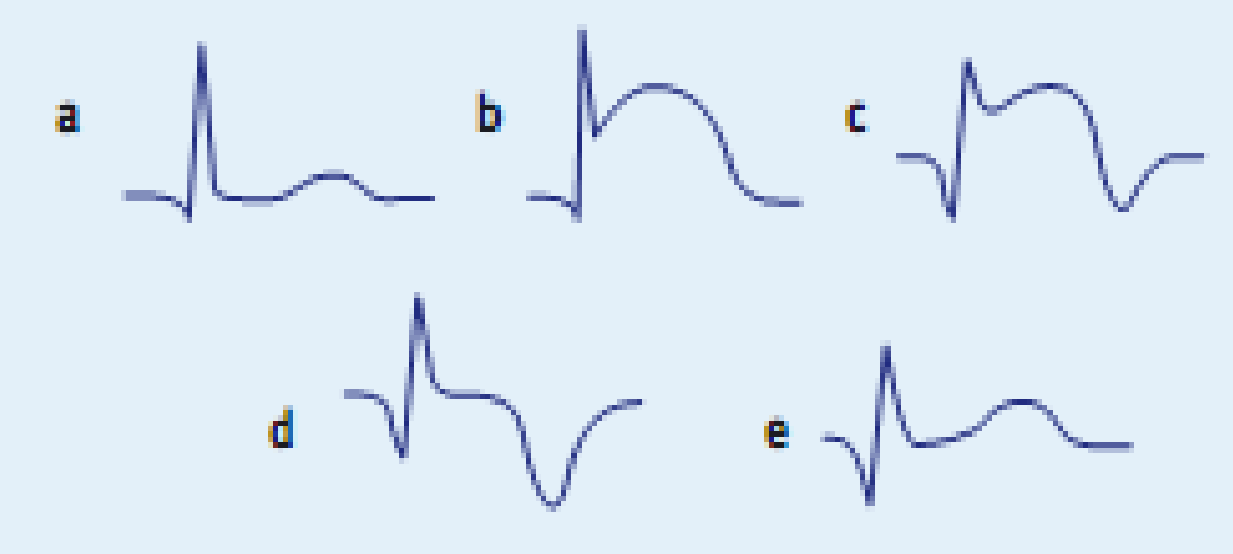

Figure 1.8 Sequential changes of acute MI. 
Control, normal appearances are shown in the lead, which, as can be seen by its QRS morphology, lies facing the left ventricle.

The typical, convex upwards S-T elevation is shown occurring within hours of the onset of symptoms of infarction. At this stage, there is no change in the QRS complex.

The appearances within days of the onset are shown. There is loss of $\mathrm{R}$ wave height, abnormal $\mathrm{Q}$ waves (in this case in both depth and duration) have developed, and there is $T$ wave inversion. The loss of $R$ wave height and the abnormal $Q$ waves prove infarction. The S-T segment and $\mathrm{T}$ wave changes indicate that the event is recent.

Resolution of the S-T segment change is shown. In other respects, the appearances are similar to $\mathrm{c}$. The loss of $\mathrm{R}$ wave height and the abnormal $\mathrm{Q}$ waves prove infarction. The normal S-T segment indicates that the event is not very recent (i.e. not within days) but $\mathrm{T}$ wave changes indicate that the event is relatively recent (within weeks).

Restoration of an upright $\mathrm{T}$ wave is shown, but this is otherwise similar to $\mathrm{d}$. The loss of $\mathrm{R}$ wave height and the abnormal $\mathrm{Q}$ waves prove infarction. The normal S-T segment indicates that the event is not very recent (i.e. not within days) and the normal $\mathrm{T}$ wave that the event is relatively old (not within weeks).

\section{Cardiac Marker}

Medical tests that are often referred to as cardiac markers include $(1,49)$ :

Cardiac troponin (the most sensitive and specific test for myocardial damage)

Creatine kinase (CK, also known as phosphocreatine kinase or creatine phosphokinase)

Aspartate transaminase (AST, also called Glutamic Oxaloacetic Transaminase (GOT/SGOT) or aspartate aminotransferase (ASAT)).

Lactate dehydrogenase (LDH)
Myoglobin ( $\mathrm{Mb})$ has low specificity for myocardial infarction and is used less than the other markers.

Cardiac markers or cardiac enzymes are proteins from cardiac tissue found in the blood. These proteins are released into the bloodstream when damage to the heart occurs, as in the case of MI. Depending on the marker, it can take between 2 to 24 hours for the level to increase in the blood. Additionally, determining the levels of cardiac markers in the laboratory - like many other lab measurements - takes substantial time. Cardiac markers are therefore not useful in diagnosing a MI in the acute phase. Also these enzyme levels are not elevated immediately following a heart attack, patients presenting with chest pain are generally treated with the assumption that a MI has occurred and then evaluated for a more precise diagnosis. (50) The clinical presentation and results from an ECG are more appropriate in the acute situation. Now a day's novel cardioprotective "urocortins" and "endoglin" determination is used as a novel prognostic marker after AMI. $(51,52)$

\section{Histopathology}

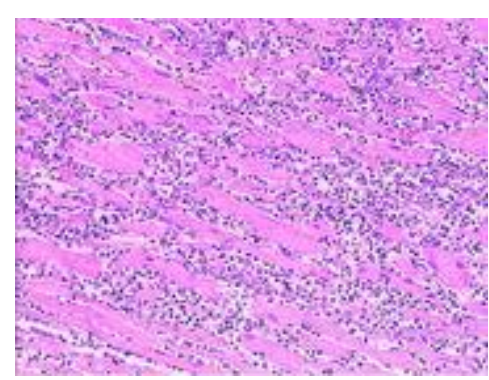

Figure 1.9 Microscopy image (magn. ca 100x, H\&E stain) from autopsy specimen of myocardial infarct (7 days postinfarction).

Histopathological examination of the heart may reveal infarction at autopsy. Under the microscope, MI presents as a circumscribed area of ischemic, coagulative necrosis (cell death). On gross examination, the infarct is not identifiable within the first 12 hours. (53) 


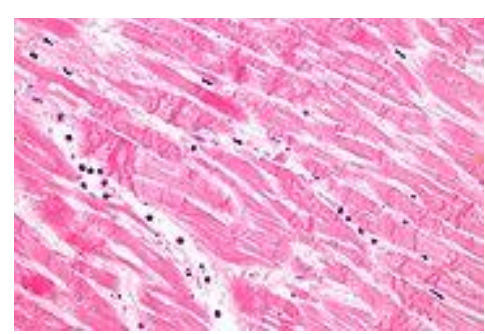

Figure 1.10 Micrograph of a MI (ca. 40x

H\&E stain) with prominent contraction band necrosis.

Although earlier changes can be discerned using electron microscopy, one of the earliest changes under a normal microscope are so-called wavy fibers. (54) Subsequently, the myocytes cytoplasm becomes more eosinophilic (pink) and the cells lose their transversal striations, with typical changes and eventually loss of the cell nucleus. (55) The interstitium at the margin of the infracted area is initially infiltrated with neutrophils, then with lymphocytes and macrophages, who phagocytes ("eat") the myocytes debris. The necrotic area is surrounded and progressively invaded by granulation tissue, which will replace the infarct with a fibrous (collagenous) scar (which are typical steps in wound healing). The interstitial space (the space between cells outside of blood vessels) may be infiltrated with red blood cells. (53)

These features can be recognized in cases where the perfusion was not restored; reperfused infarcts can have other hallmarks, such as contraction band necrosis. (56)

\section{Treatment of MI}

Table 1.1 Treatment of MI (56)

\begin{tabular}{|l|l|l|}
\hline Class of drug & Action & Drug \\
\hline Beta blockers & heart's workload $\downarrow$ & $\begin{array}{l}\text { Nadolol, Metoprolol, Pindolol, } \\
\text { Bisoprolol etc. }\end{array}$ \\
\hline Diuretics & $\begin{array}{l}\text { Rid body of excess fluid and } \\
\text { salt }\end{array}$ & $\begin{array}{l}\text { Hydrochlorothiazide, Chlorothiazide, } \\
\text { Furosemide, } \\
\text { Triamterene,Spironolactone etc }\end{array}$ \\
\hline ACE inhibitors & $\begin{array}{l}\text { Prevent blood vessel } \\
\text { constriction }\end{array}$ & $\begin{array}{l}\text { Benazepril, Lisinopril, Captopril, } \\
\text { Ramipril, Fosinopril, Moexipril. }\end{array}$ \\
\hline $\begin{array}{l}\text { Calcium channel } \\
\text { blockers }\end{array}$ & $\begin{array}{l}\text { prevent blood vessel } \\
\text { constriction by blocking } \\
\text { calcium ions }\end{array}$ & $\begin{array}{l}\text { Verapamil, Diltiazem, Nifedipine. } \\
\text { Nitrates }\end{array}$ \\
\hline $\begin{array}{l}\text { Help relax the myocardium } \\
\text { and blood vessels }\end{array}$ & Nitroglycerin, Isosorbide dinitrate. \\
\hline
\end{tabular}

\section{Discussion}

Beta-blockers, angiotensin-convertingenzyme (ACE) inhibitors, and aldosterone antagonists have been shown to reduce the overall risk of death as well as the risk of major nonfatal cardiovascular events when they are administered to patients with acute myocardial infarction who also have left ventricular systolic dysfunction, clinical evidence of heart failure, or both. $(57,58)$ However, there remains a sizable subgroup of patients in whom clinical heart failure worsens despite optimal medical therapy after acute myocardial infarction. Relevant to this discussion is the observation that ACE inhibitors block only 13 percent of the total production of angiotensin II in the human heart because of the existence of ACE-independent pathways (e.g, chymase, cathepsin, and kallikrein) that convert angiotensin I to angiotensin II. (59)

These observations provided the impetus for the development of angiotensinreceptor antagonists that offer more complete protection against angiotensin II 
by directly blocking the angiotensin type I receptor.

\section{Acknowledgements}

We would like to convey our sincere gratitude towards the HJHS Journal for publishing our article.

Financial Disclosure statement: The author received no specific funding for this work.

\section{Conflict of Interest}

The authors declare that there is no conflict of interest regarding the publication of this article.

\section{References}

1. Mohan H. Textbook of Pathophysiology. $5^{\text {th }}$ Ed. New Delhi: Jaypee Brothers medical publishers (p) ltd; 2005.

2. Robert Beaglehole, et al. The World Health Report 2004 - Changing History. World Health Organization; 2004. pp. 120-4.

3. "Cause of Death - UC Atlas of Global Inequality". Center for Global, International and Regional Studies (CGIRS) at the University of California Santa Cruz; 2006 Dec 7

4. "Deaths and percentage of total death for the 10 leading causes of death: United States, National Center of Health Statistics; 2002-2003

5. Mukherjee AK. (1995). "Prediction of coronary heart disease using risk factor categories". J Indian Med Assoc 93 (8): 312-5. PMID 8713248.

6. Ghaffar A, Reddy KS and Singhi M. "Burden of non-communicable diseases in South Asia". BMJ. 2004; 328 (7443): 807-810. doi:10.1136/bmj.328.7443.807. PMID 15070638.

7. Rastogi T, Vaz M, Spiegelman D, Reddy KS, Bharathi AV, Stampfer MJ, Willett WC and Ascherio1 A. "Physical activity and risk of coronary heart disease in India". Int. J. Epidemiol. 2004;33(4):1-9.

doi:10.1093/ije/dyh042. PMID 15044412

8. Gupta R. "Escalating Coronary Heart Disease and Risk Factors in South Asians". Indian Heart Journal.2007;214-17.

9. Gupta R, Misra A, Pais P, Rastogi P and Gupta VP. "Correlation of regional cardiovascular disease mortality in India with lifestyle and nutritional factors" (PDF). International Journal of Cardiology. 2006; 108(3):291-300. Doi: 10.1016/j.ijcard.2005.05.044. PMID15978684.

10. Workers' Compensation FAQ. Prairie View A\&M University. 2006 Nov 22.

11. SIGNIFICANT DECISIONS Subject Index. Board of Industrial Insurance Appeals; 2006 Nov 22

12. "Classification of Drivers' Licenses Regulations". Nova Scotia Registry of Regulations; 2000 May 24.

13. Harrison DG, Dikalov S. Oxidative events in cell and vascular biology. In: Re RN, DiPette DJ, Schriffrin EL, et al, editors. Molecular mechanisms in hypertension. 1st edition. Abingdon (UK): Taylor \& Francis Medical Books; 2006.

14. Duthie GG, Wahle KWJ, James WPT. Oxidants, antioxidants and cardiovascular disease. Nutrition Research Reviews. 1989;2:51-62.

15. Sawyer DB, Siwik DA, Xiao L, Pimentel DR, Singh $\mathrm{K}$, Colucci WS, et al. Role of oxidative stress in myocardial hypertrophy and failure. J. Mol. Cell. Cardiol. 2002;34:379-388.

16. David GH, Maria CG. Oxidative Stress and Hyper tension. Med. Clin. N. 2009;93:621-635.

17. Scandalios JG. Oxidative stress responses- what have genome-scale studies taught us? Genome Biology. 2002; 3(7):1019.1-1019.6

18. Wassmann S, Wassmann K, Nickenig G. Regulation of antioxidant and oxidant enzymes in vascular cells and implications for vascular disease. Curr Hypertens Rep. 2006;8(1):69-78.

19. Mainzen PS, Karthick M. Preventive effect of rutin, a bioflavonoid, on lipid peroxides and antioxidants in ISO-induced myocardial infarction in rats. Preventive Effect of Rutin on Lipids, Lipoproteins, and ATPases in Normal and Isoproterenol-Induced Myocardial Infarction in Rats. J Biochem Molecular Toxicology. 2007;21;1: 701-707.

20. Stocker R, Keaney FK. Oxidative stress and atherosclerosis. In: Loscalzo J. editor; Molecular mechanisms of atherosclerosis. London and New York: Taylor \& Francis Group Pvt 1td; 2005. p. 83114.

21. Gaetani G, Ferraris A, Rolfo M, Mangerini R, Arena S, Kirkman $\mathrm{H}$, et al. Predominant role of catalase in the disposal of hydrogen peroxide within human erythrocytes. Blood. 1996; 87(4):1595-1599.

22. Allen PB, Renu V. Pathophysiology of Acute Myocardial Infarction. Med Clin N Am. 2007;91:553-572.

23. Prof. Roger G. Mark. Clinical Electrocardiography and Arrhythmias. Massachusetts Institute of Technology. Quantitative Physiology: Organ Transport Systems. 2004:1-7.

24. McSweeney JC, Cody M, O'Sullivan P, Elberson K, Moser DK, Garvin BJ, et al. Women's early warning symptoms of acute myocardial infarction. Circulation. 2003; 108(21): 2619-23.

25. Kannel WB. Silent myocardial ischemia and infarction: insights from the Framingham Study. Cardiol. Clin. 1986;4(4):583-91.

26. Davis TM, Fortun P, Mulder J, Davis WA, Bruce DG. Silent myocardial infarction and its prognosis in a community-based cohort of Type 2 diabetic patients: the Fremantle Diabetes Study. Diabetologia. 2004; 47(3):395-399.

27. Wilson PW, D'Agostino RB, Levy D, Belanger AM, Silbershatz H, Kannel WB. "Prediction of coronary heart disease using risk factor categories". Circulation. 1998;97(18):1837-47. PMID 9603539.

28. Saikku P, Leinonen M, Tenkanen L, Linnanmaki E, Ekman MR, Manninen V, Manttari M, Frick MH, Huttunen JK. "Chronic Chlamydia pneumoniae infection as a risk factor for coronary heart disease in the Helsinki Heart Study". Ann Intern Med. 1992; 116(4):273-8. PMID 1733381.

29. Andraws R, Berger JS, Brown DL. "Effects of antibiotic therapy on outcomes of patients with coronary artery disease: a meta-analysis of 
randomized controlled trials". JAMA. 2005;293 (21):2641-7.

doi:10.1001/jama.293.21.2641. PMID 15928286.

30. Muller JE, Stone PH, Turi ZG, et al. "Circadian variation in the frequency of onset of acute myocardial infarction". N. Engl. J. Med. 1985;313 (21):1315-22. PMID 2865677

31. Beamer AD, Lee TH, Cook EF, et al. "Diagnostic implications for myocardial ischemia of the circadian variation of the onset of chest pain". Am. J. Cardiol. 1987; 60(13):998-1002. doi:10.1016/0002-9149(87)90340-7.

PMID 3673917.

32. Cannon CP, McCabe $\mathrm{CH}$, Stone $\mathrm{PH}$, et al. "Circadian variation in the onset of unstable angina and non-Q-wave acute myocardial infarction (the TIMI III Registry and TIMI IIIB)". Am. J. Cardiol. 1997; 79(3):253-8. doi:10.1016/S0002-9149(97)00743-1.

33. Tofler GH, Brezinski D, Schafer AI, et al. "Concurrent morning increase in platelet aggregability and the risk of myocardial infarction and sudden cardiac death". N. Engl. J. Med. 1987;316(24):1514-8. PMID 3587281.

34. Fantidis P, Perez De Prada T, Fernandez-Ortiz A, et al. "Morning cortisol production in coronary heart disease patients". Eur. J. Clin. Invest. 2002;32(5):304-8.

doi:10.1046/j.1365-2362.2002.00988.x. PMID 12027868.

35. Yusuf S, Hawken S, Ounpuu S, Bautista L, Franzosi MG, Commerford P, Lang CC, Rumboldt Z, Onen CL, Lisheng L, Tanomsup S, Wangai P Jr, Razak F, Sharma AM, Anand SS; INTERHEART Study Investigators. "Obesity and the risk of myocardial infarction in 27,000 participants from 52 countries: a case-control study". Lancet 2005;366(9497):16409.

doi:10.1016/S0140-6736(05)676635.PMID16271645

36. Barar FSK. Essentials of Pharmacotherapeutics. $3^{\text {rd }}$ Ed. New Delhi: S. Chand; 2004.

37. Thandroyen FT, Bellotto D, Katayama A, Hagler HK, Willerson JT and Buja LM et al. Subcellular electrolyte alterations during progressive hypoxia and following reoxygenation in isolated neonatal rat ventricular myocytes. Circulation Research. 1992; 71(1):106-119.

38. Vandana SP, Suresh RN. Cardioprotective activity of Ginkgo biloba Phytosomes in isoproterenolinduced myocardial necrosis in rats: A biochemical and histoarchitectural evaluation. Experimental and Toxicologic Pathology. 2008; 60:397-404.

39. Stanley WC. Cardiac energetics during ischaemia and the rationale for metabolic interventions. Coron Artery Dis. 2001; 12 Suppl 1:S3-7.

40. Virmani R, Forman MB, Kolodgie FD. Myocardial reperfusion injury. Histopathological effects of perfluorochemical. Circulation. 1990; 81(3 Suppl IV):57-68.

41. Buja LM. Myocardial ischemia and reperfusion injury. Cardiovasc Pathol. 2005; 14(4):170-5.

42. Krijnen PA, Nijmeijer R, Meijer CJ, Visser CA, Hack CE, Niessen HW. "Apoptosis in myocardial ischaemia and infarction". J Clin Pathol. 2002; 55
(11):801-11. doi:10.1136/jcp.55.11.801. PMID 12401816

43. Gillum RF, Fortmann SP, Prineas RJ, Kottke TE. International diagnostic criteria for acute myocardial infarction and acute stroke. Am. Heart. J. 1984; 108:150-158.

44. Alpert JS, Thygesen K, Antman E, Bassand JP. Myocardial infarction redefined a consensus document of The Joint European Society of Cardiology/American College of Cardiology Committee for the redefinition of myocardial infarction. J Am Cell Cardiol. 2000; 36(3):959-69.

45. Kasper DL, Braunwald E, Fauci AS, Hauser SL, Longo DL, Jameson JL, et al. Harrison's Principles of Internal Medicine, Vol II, $16^{\text {th }}$ Ed. New Delhi: McGraw-Hill Medical Publishing Division; 2005.

46. Goldschlager N, Gold man MJ. Principles of Clinical Electrocardiography. $13^{\text {th }}$ ed. New Delhi: McGraw Hill Co-Inc.; 1989.

47. Prof. Roger G. Mark. Clinical Electrocardiography and Arrhythmias. Massachusetts Institute of Technology. Quantitative Physiology: Organ Transport Systems. 2004:1-7.

48. Davey P. ECG. Medicine. 2006; 34(4):128-135.

49. Ross GE, Bever F, Uddin Z, Devireddy L, Gardin J. Common scenarios to clarify the interpretation of cardiac markers. J. Am. Osteopath. Assoc. 2004; 104(4):165-176.

50. Braunwald E, Antman EM, Beasley JW, Califf RM, Cheitlin MD, Hochman JS et al. ACC/AHA 2002 guideline update for the management of patients with unstable angina and non-ST-segment elevation myocardial infarction: a report of the American College of Cardiology/American Heart Association Task Force on Practice Guidelines (Committee on the Management of Patients With Unstable Angina). J. Am. Coll. Cardiol. 2002; 40:1366-1374.

51. Boonprasert $\mathrm{P}$, Lailerd $\mathrm{N}$, Chattipakorn $\mathrm{N}$. Urocortins in heart failure and ischemic heart disease. Int. J. Cardiol. 2008; 127:307-312.

52. Cruz-Gonzalez I, Pabon P, Rodriguez-Barbero A, Martin-Moreiras J, Pericacho M, Sanchez PL et al. Identification of serum endoglin as a novel prognostic marker after acute myocardial infarction. J.Cell.Mol.Med. 2008; 12(3):955-961.

53. Rubin's Pathology - Clinicopathological Foundations of Medicine. Maryland: Lippincott Williams \& Wilkins. 2001. p.546. ISBN 0-78174733-3

54. Eichbaum FW. "'Wavy' myocardial fibers in spontaneous and experimental adrenergic cardiopathies" Cardiology 1975; 60(6): 358-65. PMID 782705.

55. S Roy. Myocardial infarction. Retrieved November 28, 2006.

56. Fishbein MC. "Reperfusion injury". Clin Cardiol. 1990;

13(3):213-7. doi:10.1152/ajpheart.00270.2002

57. Pfeffer MA, Braunwald E, Moye LA, et al. Effect of captopril on mortality and morbidity in patients with left ventricular dysfunction after myocardial infarction. N Engl J Med. 1992;327:669-77.

58. Pitt B, Remme W, Zannad F, et al. Eplerenone, a selective aldosterone blocker, in patients with left ventricular dysfunction after myocardial infarction. 
N Engl J Med. 2003;348:1309-21. [Erratum, N Engl J Med 2003;348:2271.]

59. Urata H, Healy B, Stewart RW, Bumpus FM, Husain A. Angiotensin II-forming pathways in normal and failing human hearts.Circ Res. 1990;66:883-90. 